\title{
Performance Analysis of Bang-Bang and d - q Reference Frame Control Schemes for Power Quality Improvement of Grid Connected Wind Energy System
}

\author{
Shiny K. George \\ Dept. of Electrical \& Electronics \\ Engineering \\ SJCET, Palai
}

\author{
Polly Thomas \\ Dept. of Electrical \& Electronics \\ Engineering \\ Saintgits College \\ Of Engineering
}

\begin{abstract}
The generation of power is really a challenge now a days with the increase in demand for Electricity due to increase in industrialization. It is necessary to meet the energy needs by utilizing the renewable energy resources like wind, biomass, hydro co-generation, etc. Injection of the wind power into an electric grid affects the power quality. The main power quality issues are voltage sag, swell, flickers, harmonics etc. In this proposed scheme STATic COMpensator (STATCOM) is connected at the point of common coupling with a battery energy storage system (BESS) to mitigate the power quality issues. The battery energy storage is integrated to sustain the real power source under fluctuating wind power. Here two control schemes for STATCOM are compared: Bang-Bang current controller and control in $\mathrm{d}-\mathrm{q}$ reference frame. BangBang controller is a hysteresis current controlled technique. The operation of the two STATCOM control schemes for maintaining the power quality of the grid connected wind energy system is investigated using MATLAB/SIMULINK.
\end{abstract}

\section{Keywords}

STATCOM, power quality, wind generating system, Battery Energy Storage System (BESS),Bang -Bang current controller

\section{INTRODUCTION}

"Any power problem manifested in voltage, current and frequency that result in failure or maloperation of the customer equipment" is defined as power quality [1]. Injection of the wind power or any other renewable energy resources into an electric grid affects the power quality [2].

The devices used for mitigation of power quality problems are known by the name of Custom Power Devices (CPDs). The compensating devices mainly are: Static Synchronous Compensator (STATCOM), Dynamic Voltage Restorer (DVR) and Unified Power Quality Conditioner (UPQC). The work analyses the performance of STATic COMpensator (STATCOM) with a battery energy storage system (BESS) which is connected at the point of common coupling of wind energy generating system and the existing power system to reduce the power quality issues [1].

Wind turbine produces a continuous variable output power during normal operation. These power variations are mainly caused by the effect of turbulence, wind shear, and towershadow and of control system in the power system. Thus, the system needs to manage for such fluctuations. The voltage sag, swell, flickers, harmonics etc. are the main power quality issues[2]. One of the simple methods of running a wind generating system is to use the induction generator connected directly to the grid system. The induction generator has inherent advantages of cost effectiveness and robustness. However; induction generators require reactive power for magnetization. When the generated active power of an induction generator is varied due to wind, absorbed reactive power and terminal voltage of an induction generator can be significantly affected [3]. A STATCOM based control technology has been proposed for mitigating the power quality issues when we are integrating wind farms to the grid. In the event of increasing grid disturbance, a battery energy storage system for wind energy generating system is generally required to compensate the fluctuation generated by wind turbine. Here two control schemes for STATCOM is analysed and compared: Bang-Bang current controller and control in $\mathrm{d}-\mathrm{q}$ reference frame.

\section{POWER QUALITY IMPROVEMENT TOPOLOGY}

The Static Compensator (STATCOM) is a three- phase voltage source inverter having the capacitance on its DC link and connected at the point of common coupling. The STATCOM injects a compensating current of variable magnitude and frequency component at the bus of common coupling [4]. Here the utility source, wind energy system and STATCOM with BESS is connected to the grid. The STATCOM based current controlled voltage source inverter injects the current into the grid in such a way that the source current are harmonic free and they are in phase-angle with respect to source voltage. The injected current will cancel out the reactive part and harmonic part of the load and induction generator current, thus it improves the power quality [5]. This injected current generation is by proper closing and opening of the switches of voltage source inverter of STATCOM and is different for the two control schemes proposed. To accomplish these goals, the grid voltages are sensed and are synchronized in generating the current command for the inverter.

\subsection{Wind Energy Generating System(WEGS)}

Here, wind generations are based on constant speed topologies with pitch control turbine. The induction generator is used in the proposed scheme because of its simplicity, it does not require a separate field circuit, it can accept constant and variable loads, and has natural protection against short circuit. The available power of wind energy system is presented as:

$$
P_{\text {wind }}=1 / 2 \rho \mathrm{AV}_{\text {wind }}{ }^{3}
$$

Where $\rho=$ air density $\left(\mathrm{kg} / \mathrm{m}^{3}\right), A=$ area swept out by turbine blade $\left(\mathrm{m}^{2}\right), \mathrm{V}_{\text {wind }}=$ wind speed $(\mathrm{m} / \mathrm{s})$. 
It is not possible to extract all kinetic energy of wind. Thus it extract a fraction of power called power coefficient ' $\mathrm{Cp}$ ' of the wind turbine, and is given by:-

$$
\mathrm{P}_{\text {mech }}=C_{p} P_{\text {wind }}
$$

The mechanical power produced by wind turbine is given by:-

$$
\mathrm{P}_{\text {mech }}=1 / 2 \rho \Pi \mathrm{R}^{2} \mathrm{~V}_{\text {wind }}{ }^{3} C_{p}
$$

Where, $\mathrm{R}=$ Radius of the blade $(\mathrm{m})$.

\subsection{Bess-statcom}

The battery energy storage system (BESS) is used as an energy storage element for the purpose of voltage regulation [6]. The BESS will naturally maintain dc capacitor voltage constant and is best suited in STATCOM since it rapidly injects or absorbs reactive power to stabilize the grid system[6]. It also controls the distribution and transmission system in a very fast rate.

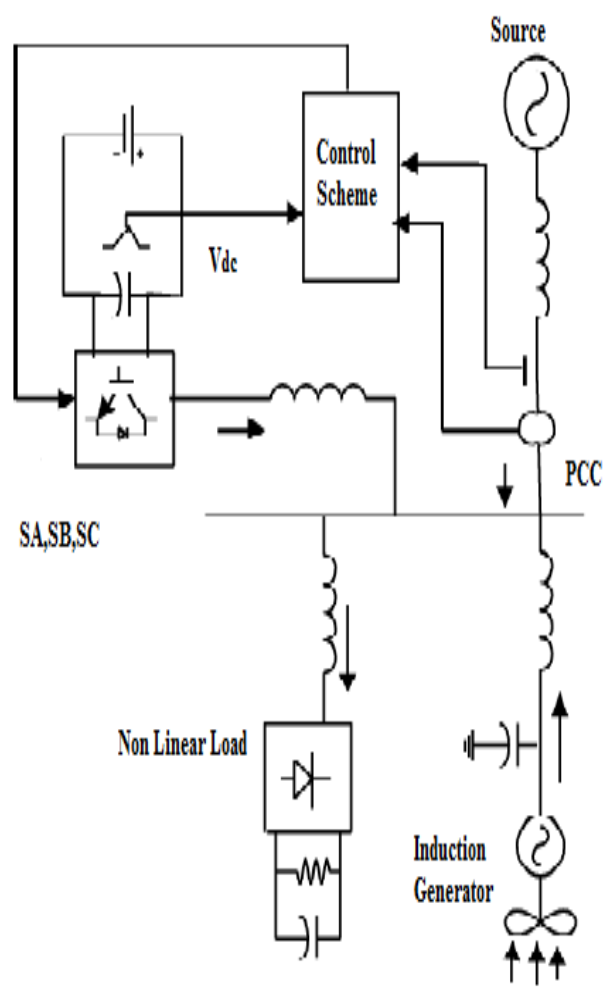

Fig.1 System operational scheme in grid system.

When power fluctuation occurs in the system, the BESS can be used to level the power fluctuation by charging and discharging operation. The battery is connected in parallel to the $\mathrm{dc}$ capacitor of STATCOM.

\subsection{System operational scheme}

The shunt connected STATCOM with battery energy storage is connected with the interface of the induction generator and non-linear load at the PCC in the grid system [7]. The Fig. 1 represents the system operational scheme in grid system. The STATCOM compensator output is varied according to the control strategy, so as to maintain the power quality norms in the grid system. A single STATCOM using insulated gate bipolar transistor is proposed to have a reactive power support, to the induction generator and to the nonlinear load in the grid system.

\subsection{Control System}

The first control scheme approach is based on injecting the currents into the grid using "bang-bang controller" [8].The controller uses a hysteresis current controlled technique as shown in Fig 2. Using such technique, the controller keeps the control system variable between boundaries of hysteresis area and gives correct switching signals for STATCOM operation. In this scheme the hysteresis band selected as 0.08 . The control algorithm needs the measurements of several variables such as three-phase source current, DC voltage inverter current with the help of sensor. The current control block, receives an input of reference current and actual current are subtracted so as to activate the operation of STATCOM in current control model [8].

The second control scheme is control in $\mathrm{d}-\mathrm{q}$ reference frame.Control of PWM-VSI has been implemented in the rotating (synchronous) $\mathrm{d}-\mathrm{q}$ reference frame because the synchronous frame controller can eliminate steady state error and has fast transient response by de-coupling control.The output is switching signals for IGBTs of STATCOM.

\subsection{Grid synchronisation}

In three-phase balance system, the RMS voltage source amplitude is calculated at the sampling frequency from the source phase voltage $\left(\mathrm{V}_{\mathrm{sa}}, \mathrm{V}_{\mathrm{sb}}, \mathrm{V}_{\mathrm{sc}}\right)$ and is expressed as sample template (sampled peak voltage), $\mathrm{V}_{\mathrm{sm}}$

$$
\mathrm{V}_{\mathrm{sm}}=\sqrt{ }\left\{2 / 3\left(\mathrm{~V}_{\mathrm{sa}}{ }^{2}+\mathrm{V}_{\mathrm{sb}}{ }^{2}+\mathrm{V}_{\mathrm{sc}}{ }^{2}\right)\right\}
$$

The in-phase unit vectors are obtained from AC source phase voltage and the RMS value of unit vector as shown below.

$$
\begin{aligned}
\mathrm{U}_{\mathrm{sa}} & =\mathrm{V}_{\mathrm{sa}} / \mathrm{V}_{\mathrm{sm}} \\
\mathrm{U}_{\mathrm{sb}} & =\mathrm{V}_{\mathrm{sb}} / \mathrm{V}_{\mathrm{sm}} \\
\mathrm{U}_{\mathrm{sc}} & =\mathrm{V}_{\mathrm{sc}} / \mathrm{V}_{\mathrm{sm}}
\end{aligned}
$$

The in-phase generated reference currents are derived using inphase unit voltage template as shown below.

$$
\mathrm{i}_{\mathrm{sa}} *=\mathrm{I} * \mathrm{U}_{\mathrm{sa}}, \mathrm{i}_{\mathrm{sb}} *=\mathrm{I} * \mathrm{U}_{\mathrm{sb}}, \mathrm{i}_{\mathrm{sc}} *=\mathrm{I}^{*} \mathrm{U}_{\mathrm{sc}}
$$

where 'I' is proportional to magnitude of filtered source voltage for respective phases. This ensures that the source current is controlled to be sinusoidal [9].

\subsection{Hysteresis current controller}

It is also named as Bang- Bang Current controller and is implemented in the current control scheme. The reference current is generated as in (6) and actual current are detected by current sensors and are subtracted for obtaining a current error for a hysteresis based bang-bang controller. Thus the ON/OFF switching signals for IGBTs of STATCOM are derived from hysteresis controller [9] .The switching function $S_{A}$ for phase ' $a$ ' is expressed as:

$$
\begin{aligned}
& i_{s a}>\left(\boldsymbol{i}_{s a} *+H B\right)=S_{A}=1 \\
& \boldsymbol{i}_{s a}<\left(\boldsymbol{i}_{s a} *-H B\right)=S_{A}=0
\end{aligned}
$$

This is same for phase 'b' and 'c'. 


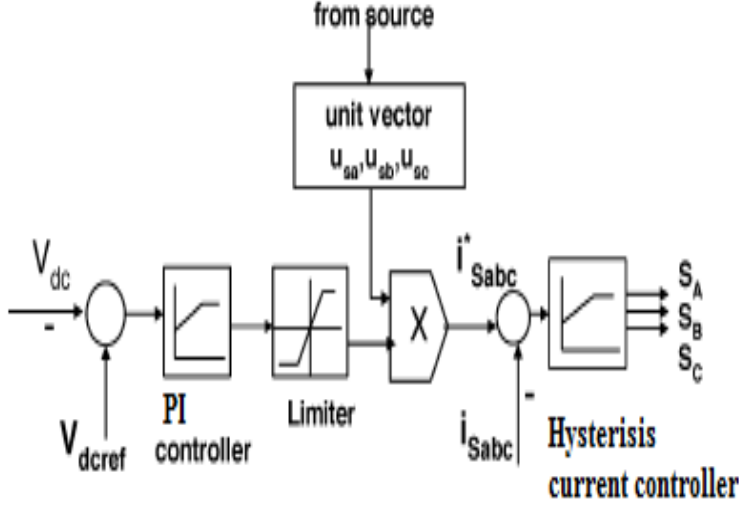

Fig.2. Control System

\subsection{Control in d-q Reference Frame}

Due to drawbacks of the conventional vector control strategy, a direct-current vector control strategy is used. A cascade control in the d-q frame is proposed. Control of PWM-VSI has been implemented in the rotating (synchronous) $\mathrm{d}$-q reference frame because the synchronous frame controller can eliminate steady state error and has fast transient response by de-coupling control. However, synchronous frame controller is more complex than the stationary frame controller and requires transforming of measured stationary frame ac current to rotating frame dc components, and transforming the result of control back to the stationary frame for implementation. It consists of outer voltage loop and inner current loop. Synchronization with the grid voltage is performed through a phase locked loop (PLL). Fig. 3 shows the PLL block diagram where the input is the measured three-phase voltage at PCC. The output signals $\mathrm{V}_{\mathrm{d}}, \theta_{\text {grid }}$, and $\omega$ are obtained to use in the $\mathrm{d}-\mathrm{q}$ frame inverter control.

The proposed control methodology is depicted in fig. 4 . The daxis outer loop controls the DC bus voltage, and the inner loop controls the active AC current. Because the inverter allows bidirectional power flow, increments in the DC bus voltage can be produced from negative or positive current direction and vice versa. The $\mathrm{q}$-axis outer loop regulates the AC voltage magnitude by adjusting the reactive current, which is controlled by the q-axis inner current loop. Additionally, d-q decoupling-terms $\omega \mathrm{L}_{\text {inv }}$ and feed-forward voltage signals are added to improve the performance during transients

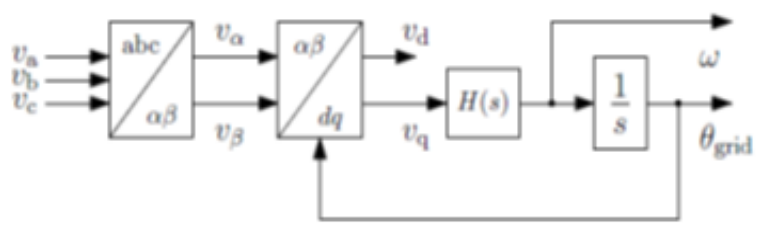

Fig.3 PLL block

The main purpose of the grid side control system is to regulate the voltage across DC Link capacitor and either of real/reactive power and the PCC voltage. The frame of the direct-current vector control strategy is a nested-loop structure including an inner current control loop and a DC-Link voltage control loop. In the DC-Link voltage control loop, the PI controller receives the difference between the DC-Link voltage reference and the measured DC-Link voltage and outputs the tuning signal as the $d$-axis current reference of the inner current control loop. Therefore, the DC-Link voltage control can also be seen as an outer loop of the inner current control loop in $d$-axis current. On the other hand, the $q$-axis current can contribute to the reactive power or PCC voltage support control. In the reactive power control mode, the $q$-axis current reference is generated through a reactive power controller.

In the AC system voltage support control mode, the $q$-axis current reference is generated through a PCC voltage controller, during which the GSC should generate a reactive power as much as possible depending on how much the PCC voltage drops. Finally, the structure of the direct current vector control strategy is demonstrated in fig. 4 .

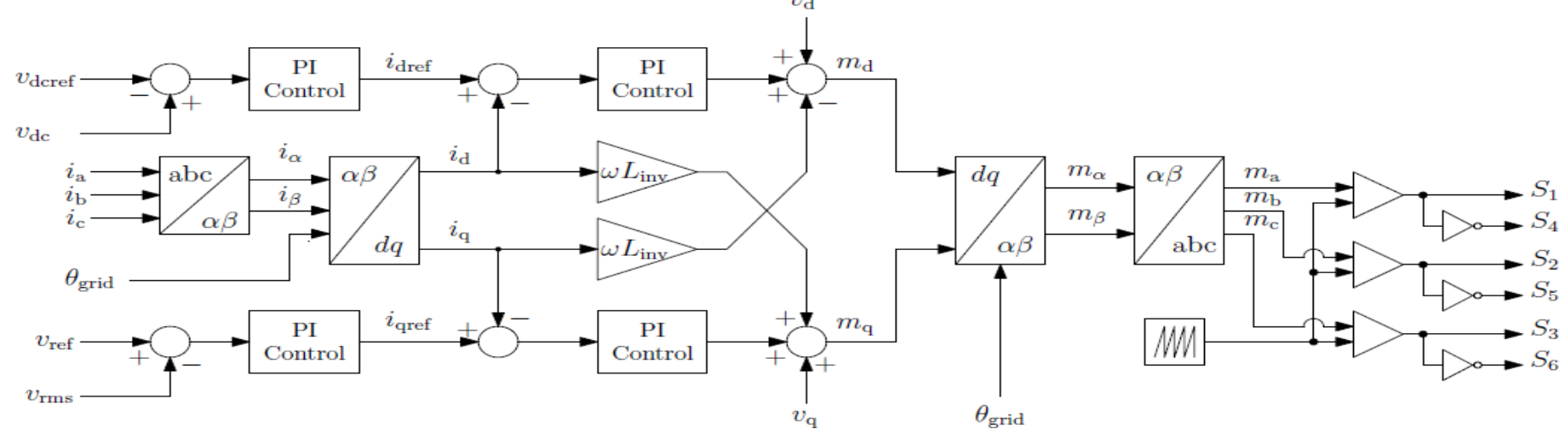

Fig. 4 d-q control

\subsection{Current Control Loop}

The inner current loop strategy is based on the below equations which represents the relationship between the GSC output voltage and the voltage and current of PCC in d-q reference frame. The equations are derived by reducing the high frequency oscillation part of the equation. This process can be achieved by a low pass filter in the real circuit.

$$
\begin{gathered}
v_{d 1}=-R i_{d}^{\prime}+\omega_{s} L i_{q}^{\prime}+v_{d} \\
v_{q 1}=-R i_{q}^{\prime}+\omega_{s} L i_{d}^{\prime}
\end{gathered}
$$




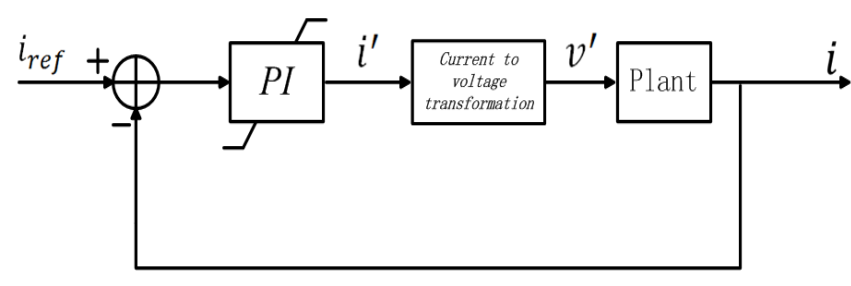

Fig 5.Current loop controller.

\subsection{DC-Link voltage control loop}

The DC-Link loop control strategy aims to stabilize the voltage over the DC-Link capacitor in an expected value, which can provide a reliable DC bus for the DC-DC converter. DC-Link control strategy can be preceded based on the power balance between the ac and dc sides. The transfer function of the DC-Link voltage loop control can be calculated by ignoring $i_{\mathrm{dc} 2}$ as interference.

$$
\begin{gathered}
v_{d c} i_{g}=v_{d} i_{d}+v_{q} i_{q}=v_{d} i_{d} \\
v_{d c}\left(C \frac{d v_{d c}}{d t}+i_{d c 2}\right)=v_{d} i_{d}
\end{gathered}
$$

$$
G_{d}(s)=\frac{V_{d}}{V_{d c} \cdot C \cdot s}
$$

The DC-Link voltage loop control scheme is shown in fig.6. Similar as the other feedback control scheme in the thesis, a PI controller is employed to minimize the error between measured dynamic voltage and reference.

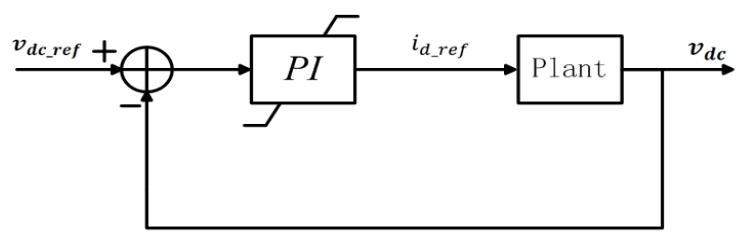

Fig 6. DC link voltage control loop.

\section{SYSTEM PERFORMANCE}

The proposed control schemes are simulated using SIMULINK in power system block set. The system parameter

\begin{tabular}{|c|c|c|}
\hline $\begin{array}{l}\text { S.L } \\
\text { No }\end{array}$ & Parameters & Ratings \\
\hline 1. & Grid voltage & 3 phase, $415 \mathrm{~V}, 50 \mathrm{~Hz}$ \\
\hline 2. & $\begin{array}{l}\text { Induction } \\
\text { Motor/Generator }\end{array}$ & $\begin{array}{l}12 \mathrm{kVA}, 415 \mathrm{~V}, 50 \mathrm{~Hz}, \\
\mathrm{Speed}=1440 \mathrm{rpm}, \mathrm{Rs}=0.005 \Omega \\
\mathrm{Rr}=0.005 \Omega, \mathrm{Ls}=0.125 \mathrm{H}, \mathrm{Lr}=0.18 \mathrm{H}\end{array}$ \\
\hline 3. & $\begin{array}{l}\text { Line series } \\
\text { Inductance }\end{array}$ & $6.37 \mathrm{mH}$ \\
\hline 4. & $\begin{array}{l}\text { Inverter } \\
\text { Parameters }\end{array}$ & $\begin{array}{l}\text { DC link voltage }=800 \mathrm{~V} \\
\text { DC link capacitance }=6000 \mu \mathrm{F} \\
\text { Switching frequency }=2 \mathrm{kHz}\end{array}$ \\
\hline 5. & Load parameter & Non linear load $25 \mathrm{~kW}$ \\
\hline 6. & Wind turbine & $\begin{array}{l}\text { Base wind speed }=11 \mathrm{~m} / \mathrm{s} \\
\text { Pitch angle }(\beta)={ }^{\prime} 0 ' \text { deg }\end{array}$ \\
\hline
\end{tabular}
for the system is given Table 1.

Table 1System Parameters

\subsection{Voltage Source Current Control- Inverter Operation}

The three phase injected current into the grid from STATCOM will cancel out the distortion caused by the nonlinear load and wind generator. The IGBT based threephase inverter is connected to grid through the transformer. The generation of switching signals from reference current is simulated within hysteresis band of 0.08[1] for Bang-Bang current controller. The choice of narrow hysteresis band switching in the system improves the current quality.

The choice of the current band depends on the operating voltage and the interfacing transformer impedance. The compensated current for the nonlinear load and demanded reactive power is provided by the inverter. The real power transfer from the batteries is also supported by the controller of this inverter. The three phase inverter injected current are shown in Fig. 8.

\subsection{STATCOM-Performance Under Load Variations}

The wind energy generating system is connected with grid having the nonlinear load. The bang-bang current controller and control in d-q reference frame for the STATCOM is implemented in MATLAB/SIMULINK .The outcome of STATCOM compensating harmonics and balancing source current has been demonstrated. The main SIMULINK diagram of the control schemes with STATCOM is shown in fig 7. The nonlinear load used a bridge rectifier with RL load.

The performance of the system is measured by switching the STATCOM at time $\mathrm{T}=0.05 \mathrm{~s}$ in the system and how the STATCOM responds to the step change command for increase in additional load at time $\mathrm{T}=0.2 \mathrm{~s}$ as shown in the Fig 8.The load current and source current are shown in Fig. 9(a) and Fig.9(b) respectively. While the injected current from STATCOM is shown in Fig. 9(d) and the generated current from wind generator at PCC is depicted in Fig.9(c).

When STATCOM controller is made ON, without change in any other load condition parameters, it starts to mitigate for reactive demand as well as harmonic current [1].The additional demand is fulfil by STATCOM compensator with the help of BESS. This can be easily seen in the source current (grid current).Because whatever changes in the load or induction generator occurs it can't be seen in the source current and it is free from harmonics.

The DC link voltage regulates the source current in the grid system, so the DC link voltage is maintained constant across the capacitor [1] as in Fig.10.System is analysed and performance of the system is evaluated. One of the easiest measurements of harmonics is the total harmonic distortion (THD) measurement through FFT analysis. The Fourier analysis of this waveform with and without using Bang-Bang controller for STATCOM is performed and the THD of this source current at PCC without STATCOM is $11.26 \%$ and the THD of source current (grid current) with STATCOM is only $1.95 \%$. as shown in Table 2. The injected currents also have harmonics and it cancel out reactive and harmonic part produced by the load and induction generator. Thus improves the power quality. 


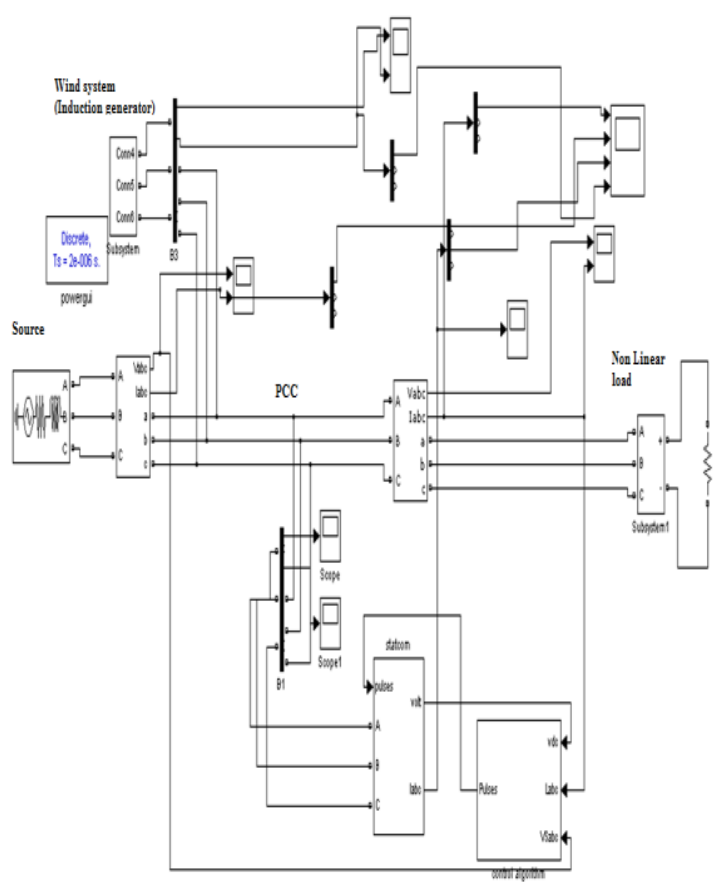

Fig 7. SIMULINK diagram of the system

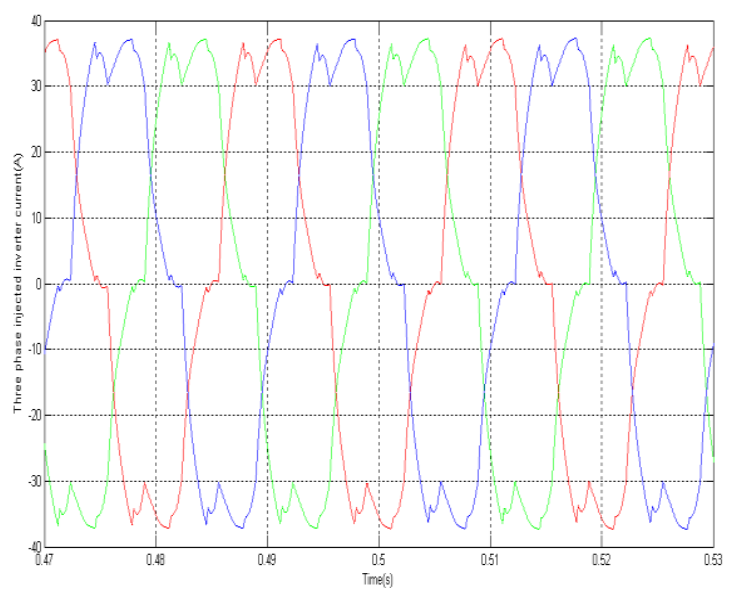

Fig.8. Three phase injected inverter Current.

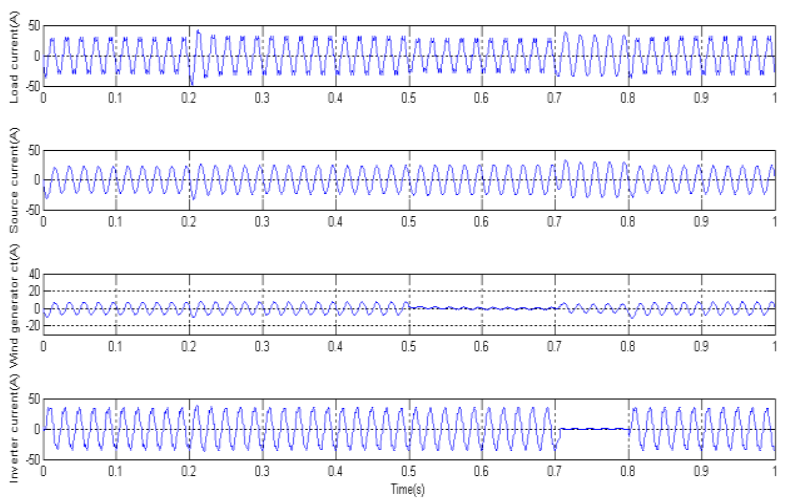

Fig. 9(a)Load Current (b) Source Current. (c) Wind generator (Induction generator) current. (d) Inverter Injected Current.

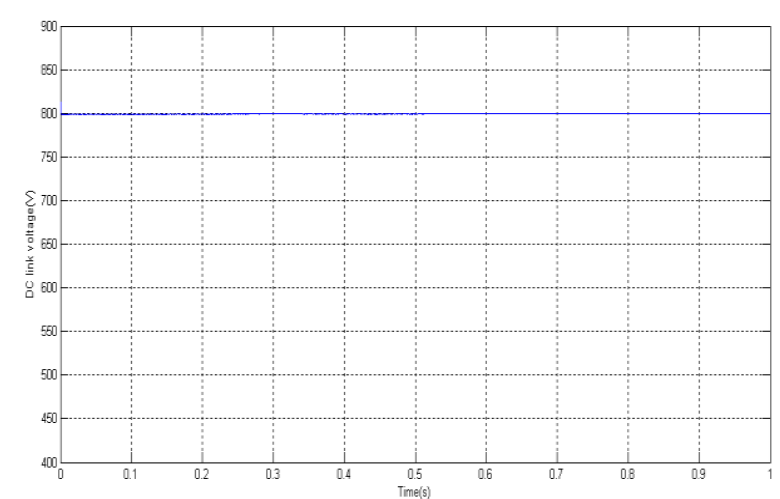

Fig.10. DC link voltage.

Table 2Results comparison by FFT analysis

\begin{tabular}{|l|l|l|}
\hline SLNo. & Current & THD(\%) \\
\hline 1 & Load current & 22.65 \\
\hline 2 & wind generator| current & 15.11 \\
\hline 3 & Inverter injected current & 10.92 \\
\hline 4 & Source current (without STATCOM) & 11.26 \\
\hline 5 & Source current (with STATCOM) & 1.95 \\
\hline
\end{tabular}

\subsection{Implementation of control in d-q reference frame}

The model of this system is also developed in MATLAB/SIMULINK. To investigate the performance of the system a load variation is inserted at time $\mathrm{T}=0.2 \mathrm{~s}$. as shown in Fig.11. It shows the load current, inverter injected current, wind generator current and source current. The power quality improvement is observed at point of common coupling, when the controller is in ON condition. The STATCOM is placed in the operation at $0.05 \mathrm{~s}$ The above tests with proposed scheme has not only power quality improvement feature but it also has sustain capability to support the load with the energy storage through the batteries. It is observed that the source current on the grid is affected due to the effects of nonlinear load and wind generator, thus purity of waveform may be lost on both sides in the system [1]. As in Table 3, It is shown that the source current THD has been improved considerably and within the norms of the standard.
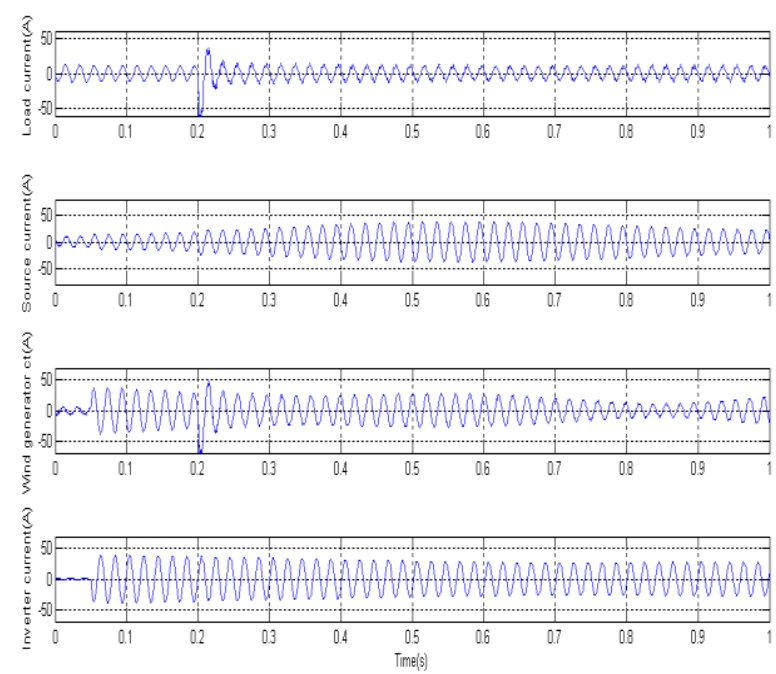

Fig.11. (a) Load Current (b) Source Current(c) Wind generator (Induction generator) current (d) Inverter Injected current 
Table 3.Results comparison by FFT analysis

\begin{tabular}{|c|l|c|}
\hline SL.No & \multicolumn{1}{|c|}{ Current } & THD(\%) \\
\hline 1. & Load current & 20.21 \\
\hline 2. & Wind Generator Current & 14.16 \\
\hline 3. & Inverter injected current & 5.33 \\
\hline 4. & $\begin{array}{l}\text { Source current(without } \\
\text { STATCOM) }\end{array}$ & 3.88 \\
\hline 5. & $\begin{array}{l}\text { Source current(with } \\
\text { STATCOM) }\end{array}$ & 0.61 \\
\hline
\end{tabular}

The current waveform before and after the STATCOM operation is analysed. Without using $\mathrm{d}-\mathrm{q}$ reference frame controller for STATCOM the source current FFT is 3.88\%, and using controller the source current (grid current) FFT is reduced to $0.61 \%$ as shown in Table 3 . It indicates that when we are using $\mathrm{d}$-q reference frame controller the harmonics are reduced more as compared to Bang -Bang controller.

\section{CONCLUSION}

The paper presents the STATCOM-based control scheme for power quality improvement in grid connected wind generating system and with non linear loads.

The operation of the control system developed for theSTATCOM-BESS in MATLAB/SIMULINK for maintaining the power quality is simulated using two controllers: Bang-Bang current controller and d-q reference frame controller .STATCOM injects current to the grid and it cancel out the reactive and harmonic parts of the induction generator current and load current. When we are reducing the wind generating system output, it will not affect the source current magnitude by the two controllers.

The THD analysis revealed that the d-q reference frame logic controller is good compared to bang-bang controller. The d-q reference frame controller is more complex and has faster response. The integrated wind generation and STATCOM with BESS have shown the outstanding performance.

\section{REFERENCES}

[1] Sharad W. Mohod, Mohan V. Aware "A STATCOM control scheme for grid connected wind energy system for power quality improvement IEEE SYSTEMS JOURNAL, VOL. 4, NO. 3, SEPTEMBER 2010

[2] C. Han, A. Q. Huang, M. Baran, S. Bhattacharya, and W. Litzenberger, "STATCOM impact study on the integration of a large wind farm into a weak loop power system," IEEE Trans. Energy Conv., vol. 23, no. 1,pp. 226-232, Mar. 2008.
[3] M. I. Milands, E. R. Cadavai, and F. B. Gonzalez, "Comparison of control strategies for shunt active power filters in three phase four wire system," IEEE Trans. Power Electron., vol. 22, no. 1, pp. 229-236, Jan. 2007.

[4] Sharad W. Mohod, Member, IEEE, and Mohan V. Aware "Micro wind power generator with battery storage" IEEE SYSTEMS JOURNAL, VOL. 6, NO. 1, MARCH 2012

[5] S. W. Mohod and M. V. Aware, "Power quality issues \& it's mitigation technique in wind energy conversion," in Proc. of IEEE Int. Conf. Quality Power \& Harmonic, Wollongong, Australia, 2008.

[6] J. J. Gutierrez, J. Ruiz, L. Leturiondo, and A. Lazkano, "Flicker measurement system for wind turbine certification," IEEE Trans. Instrum. Meas., vol. 58, no. 2, pp. 375-382, Feb. 2009.

[7] S. Sabna, D. Prasad, R. Shivakumar, "Power System Stability Enhancement by Neuro Fuzzy Logic Based SVC for Multi Machine System", ,IJEAT, ISSN: 2249 8958, Volume-1, Issue-4, April 2012

[8] N.Karpagam , D.Devaraj , "Fuzzy Logic Control of Static Var Compensator for Power System Damping" International Journal of Electrical and Electronics Engineering, October 2009

[9] T.Kinjo and T. Senjyu, "Output levelling of renewable energy by electric double layer capacitor applied for energy storage system," IEEE Trans. Energy Conv., vol. 21, no. 1, Mar. 2006

\section{AUTHOR PROFILE}

Shiny K George - Received B-Tech in Electrical \& Electronics from St. Joseph's College of Engineering and Technology , Palai Kerala under the Mahatma Gandhi University in 2010 . She received M-Tech in Power Systems under Mahatma Gandhi University. Currently working as Asst. Professor at St. Joseph's College of Engineering and Technology, Palai .Areas of interest are teaching and research in renewable energy sources.

Polly Thomas - Received B-Tech in Electrical \& Electronics from St. Joseph's College of Engineering and Technology, Palai Kerala under the Mahatma Gandhi University in 2010 . $\mathrm{He}$ received M-Tech in Power Systems under Mahatma Gandhi University. Currently working as Asst. Professor at SAINTGITS College of Engineering,Pathamuttom,Kottayam. 